\title{
Fitorremediação de solos contaminados por ferro (Fe) na forma de sulfato ferroso (FeSO4) utilizando a espécie Mimosa bimucronata (DC.) Kuntze
}

Popularmente conhecida como Maricá ou arranha-gato, a Mimosa bimucronata (DC.) Kuntze é considerada uma árvore ou arbusto arborescente, aculeada, comumente com 3 a $10 \mathrm{~m}$ de altura, particularmente adaptável a diferentes tipos de solos e climas, apresenta alto poder germinativo (em média $70 \%$ ), em suas características apresenta raiz pivotante muito comprida favorecendo a absorção de nutrientes e minerais do solo e tende a alcançar a maturidade em 7 anos. Na fitorremediação os vegetais podem atuar de forma direta ou indireta na redução ou remoção dos contaminantes. Na remediação direta, os compostos são absorvidos e acumulados ou metabolizados nos tecidos, através da mineralização dos mesmos. Na forma indireta, os vegetais extraem contaminantes das águas subterrâneas, reduzindo assim a fonte de contaminação ou quando a presença de plantas propicia meio favorável ao aumento da atividade microbiana, que degrada o contaminante. O seguinte trabalho teve como objetivo verificar a efetividade do uso de Mimosa bimucronata (DC.) Kuntze como espécie fitorremediadora em Latossolo Roxo contaminado por diferentes concentrações de ferro na forma de sulfato ferroso (FeSO4).

Palavras-chave: Maricá; Absorção; Latossolo Roxo.

\section{Phytorremediation of iron contaminated soils (Fe) in the form of ferrous sulfate (FeSO4) using the species Mimosa bimucronata (DC.) Kuntze}

\begin{abstract}
Popularly known as Maricá or skyscraper, Mimosa bimucronata (DC.) Kuntze is considered an arboreal tree or shrub, accented, commonly 3 to $10 \mathrm{~m}$ high, particularly adaptable to different types of soils and climates, with high germinative power (on average $70 \%$ ), in its characteristics it has a very long pivoting root favoring the absorption of nutrients and minerals from the soil and tends to reach maturity in 7 years. In phytoremediation plants can act directly or indirectly to reduce or remove contaminants. In direct remediation, the compounds are absorbed and accumulated or metabolized in the tissues, through their mineralization. Indirectly, vegetables extract contaminants from groundwater, thus reducing the source of contamination or when the presence of plants provides a favorable environment for increasing microbial activity, which degrades the contaminant. The following work aimed to verify the effectiveness of using Mimosa bimucronata (DC.) Kuntze as a phytoremediation species in an Oxisol contaminated by different concentrations of iron in the form of ferrous sulfate (FeSO4).
\end{abstract}

Keywords: Maricá; Absorption; Oxisol.

Topic: Ciências do Solo

Reviewed anonymously in the process of blind peer.
Received: 08/06/2021

Approved: 24/06/2021
André Luiz Maciel

Universidade Tecnológica Federal do Paraná http://lattes.cnpq.br/0644714686303048 andre98maciel@gmail.com

Haniel Fernando Ayoub Casalvara (D) Universidade Tecnológica Federal do Paraná http://lattes.cnpq.br/2224873000003447 http://orcid.org/0000-0002-0887-2888 haniel.fernando@hotmail.com

Júlio Diogenes Schuquel Tomé (D) Universidade Tecnológica Federal do Paraná http://lattes.cnpq.br/4123601467176024 http://orcid.org/0000-0002-2840-2410 juliodtome@gmail.com

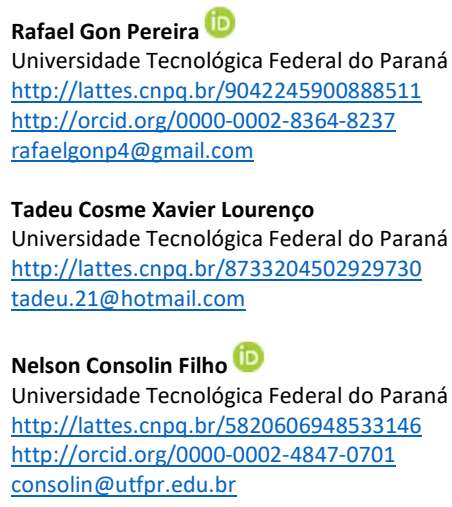

José Hilton Bernardino de Araújo (it) Universidade Tecnológica Federal do Paraná http://lattes.cnpq.br/4560874870987991 http://orcid.org/0000-0001-9743-7855 jaraujo@utfpr.edu.br

DOI: 10.6008/CBPC2179-6858.2021.006.0002

Referencing this:

MACIEL, A. L.; CASALVARA, H. F. A.; TOMÉ, J. D. S.; PEREIRA, R. G.; LOURENÇO, T. C. X.; CONSOLIN FILHO, N.; ARAÚJO, J. H. B.. Fitorremediação de solos contaminados por ferro ( $\mathrm{Fe}$ ) na forma de sulfato ferroso (FeSO4) utilizando a espécie Mimosa bimucronata (DC.) Kuntze. Revista Ibero Americana de Ciências Ambientais, v.12, n.6, p.20-29, 2021. DOI: http://doi.org/10.6008/CBPC2179$\underline{6858.2021 .006 .0002}$ 


\section{INTRODUÇÃO}

Com um cenário constante de aumento populacional surge a necessidade de buscar alternativas para melhorar a qualidade de vida. Essa necessidade demanda desenvolvimento e por consequência o aumento das indústrias, uso excessivo de agrotóxicos e instalação de novos empreendimentos, esses por sua vez provocam alteração química considerável no solo alterando a concentração natural de metais pesados (RAMALHO et al., 2000).

A contaminação de solos com metais pesados é cada vez mais frequente e preocupante por causa do impacto negativo desses elementos no ecossistema (RIBEIRO FILHO et al., 2001). Os metais ocorrem naturalmente nos solos, mas quando somados aos efeitos das atividades humanas causam diversos danos (BIOTECH, 2006). Como exemplo tem-se o ferro que é um micronutriente essencial para a manutenção da vida, porém está pouco disponível na maioria dos solos, em plantas ele está relacionado a diversas atividades metabólicas, participando da formação de algumas enzimas (catalase, peroxidase, citocromo oxidase e xantina oxidase), além de ser indispensável nos processos de respiração, fotossíntese e fixação de $\mathrm{N}$ (ALENXANDRE et al., 2012).

Para a remediação de solos contaminados por metais pesados, diversas técnicas têm sido propostas, alguns desses procedimentos são: remoção da camada contaminada; adição de uma cobertura de solo não contaminado; lixiviação dos metais com ácidos ou quelatos; aplicação de corretivos capazes de elevar o pH e adição de materiais orgânicos (LEVY et al., 1992; Ll et al., 1996; SIQUEIRA et al., 1999). Essas tecnologias são muito variáveis, conforme a matriz contaminada, a natureza do contaminante, o nível de contaminação e a disponibilidade de recursos. No presente estudo foi dado ênfase a técnica de fitorremediação, que faz uso de plantas e seus microrganismos associados, visando o tratamento in situ de solos contaminados com ferro (TAVARES, 2009).

A fitorremediação de áreas poluídas é bastante útil para o meio ambiente devido à utilização de plantas específicas, no intuito de amenizar ou até mesmo despoluir totalmente áreas contaminadas (COUTINHO et al., 2007).

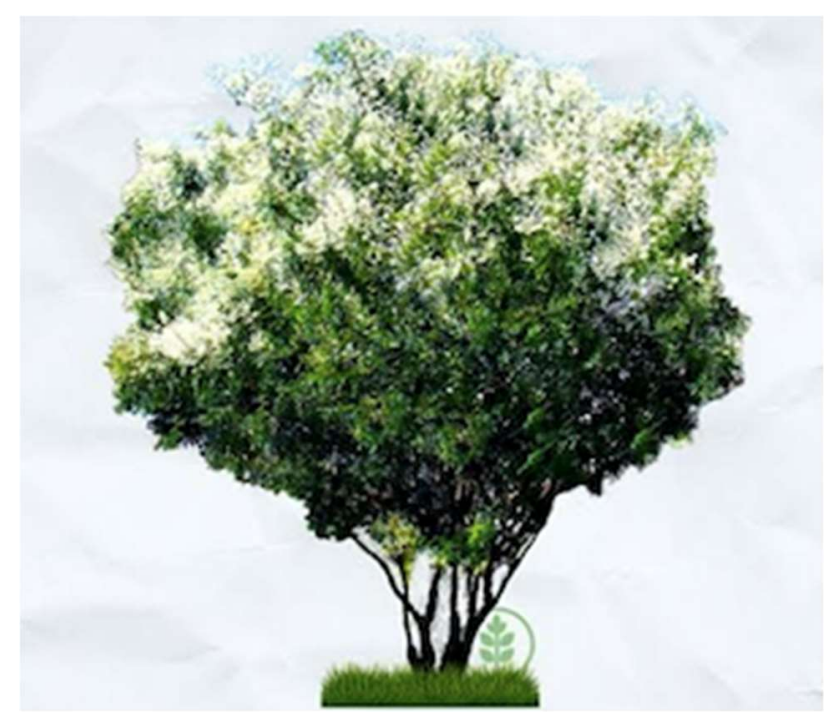

Figura 1: Espécie da Mimosa bimucronata (DC.) Kuntze. 
Para Amado (2015) caso a espécie vegetal testada para a fitorremediação sobreviva a fase de muda (muito suscetível a fitotoxicidade) e demonstre capacidade de acumular concentrações elevadas de metais pesados, passa a ser promissora para o tratamento de solos contaminados.

Conforme considerações de Henrique Douglas Coutinho e Alyne Rats Barbosa, é necessário a utilização de plantas que possuam determinadas características como uma boa capacidade de absorção, sistema radicular profundo, acelerada taxa de crescimento, fácil colheita e que apresentem uma grande resistência ao poluente, sendo assim justifica-se a utilização da espécie da Mimosa bimucronata (DC.) Kuntze (Figura 1).

\section{MATERIAIS E MÉTODOS}

Foram coletadas 12 amostras de solo do bosque da Universidade Tecnológica Federal do Paraná Campus Campo Mourão sendo que desta foram escolhidas três amostras para Controle e as seguintes foram divididas em triplicatas sendo contaminadas com três concentrações distintas de ferro: 0,3, 0,6 e 1,2 mg/kg. Em cada recipiente adicionou-se aleatoriamente sementes de Mimosa bimucronata (DC.) Kuntze.

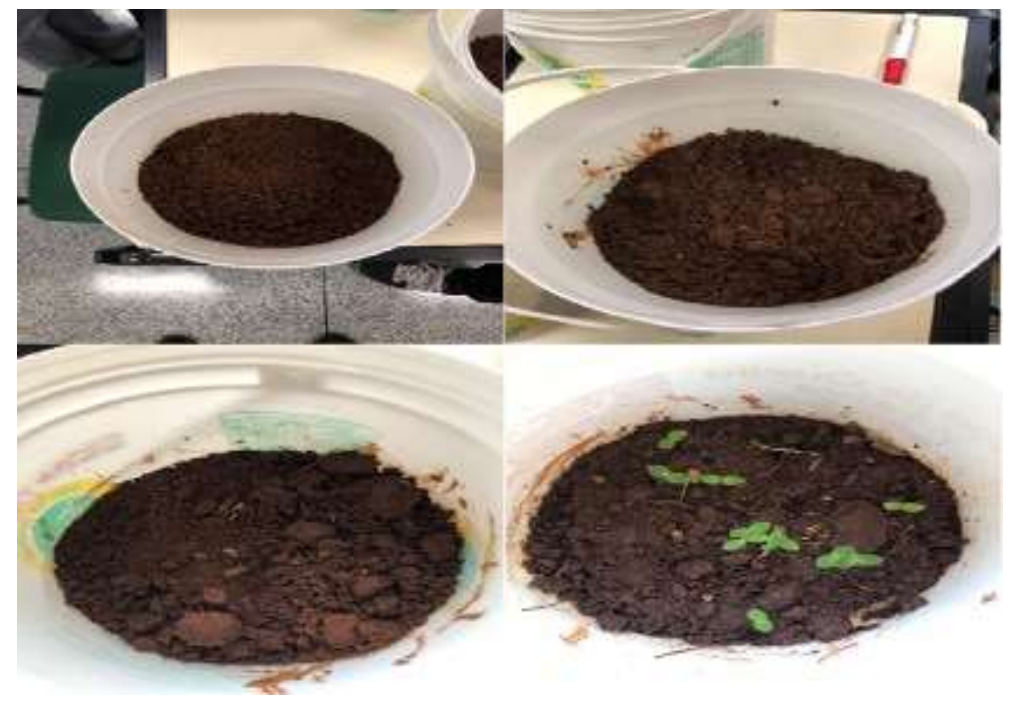

Figura 2: Plantas no estágio inicial de desenvolvimento.

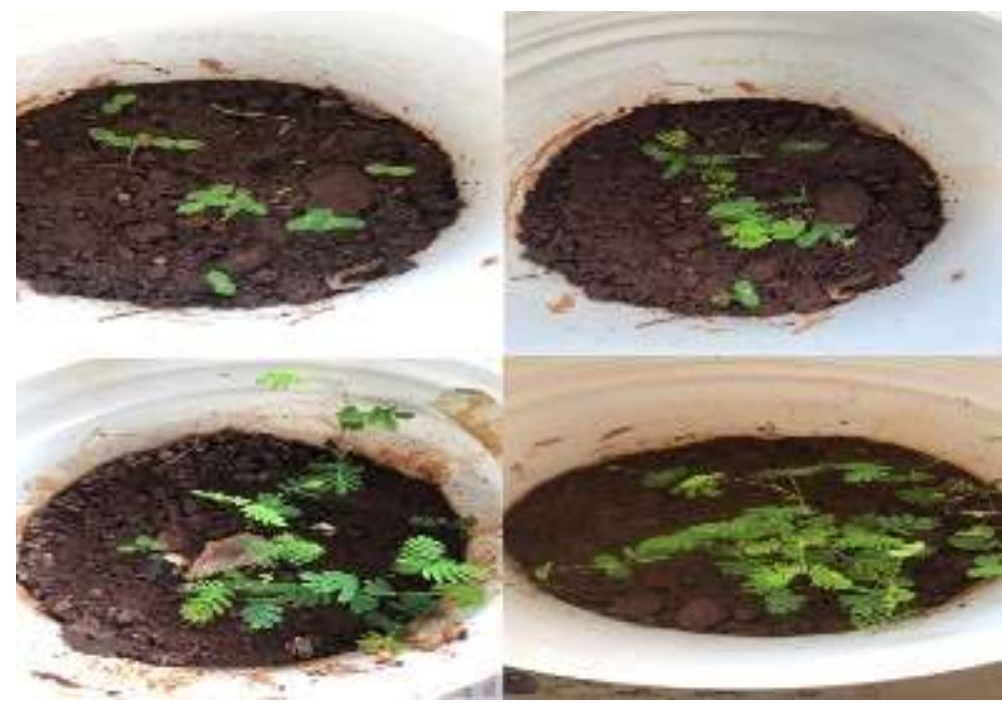

Figura 3: Plantas em estágio intermediário de desenvolvimento. 


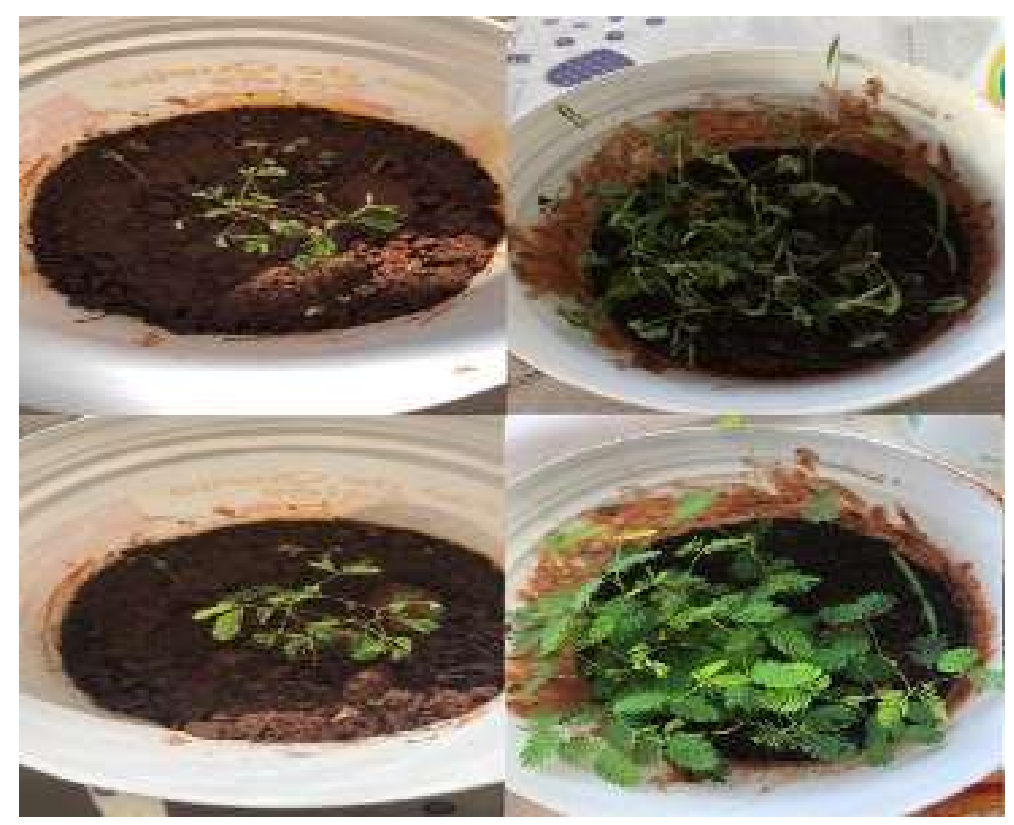

Figura 4: Plantas no dia da retirada.

Feita essa divisão o experimento foi mantido em local com irrigação controlada por um período de 30 dias. $\mathrm{O}$ acompanhamento do experimento foi realizado diariamente, sendo feito a rega das amostras de acordo com a necessidade das plantas e fotografadas (Figuras 2, 3, 4) para a comparação do crescimento entre elas.

Após o término dos 30 dias, foi realizada a retirada das amostras de Mimosa bimucronata (DC.) Kuntze para avaliar o comprimento da raiz e caule, como mostrado na Figura 5. Com a retirada para as medidas, as plantas foram colocadas em cadinhos de porcelana e levadas ao forno mufla a $500^{\circ} \mathrm{C}$ durante duas horas para a calcinação da matéria orgânica.

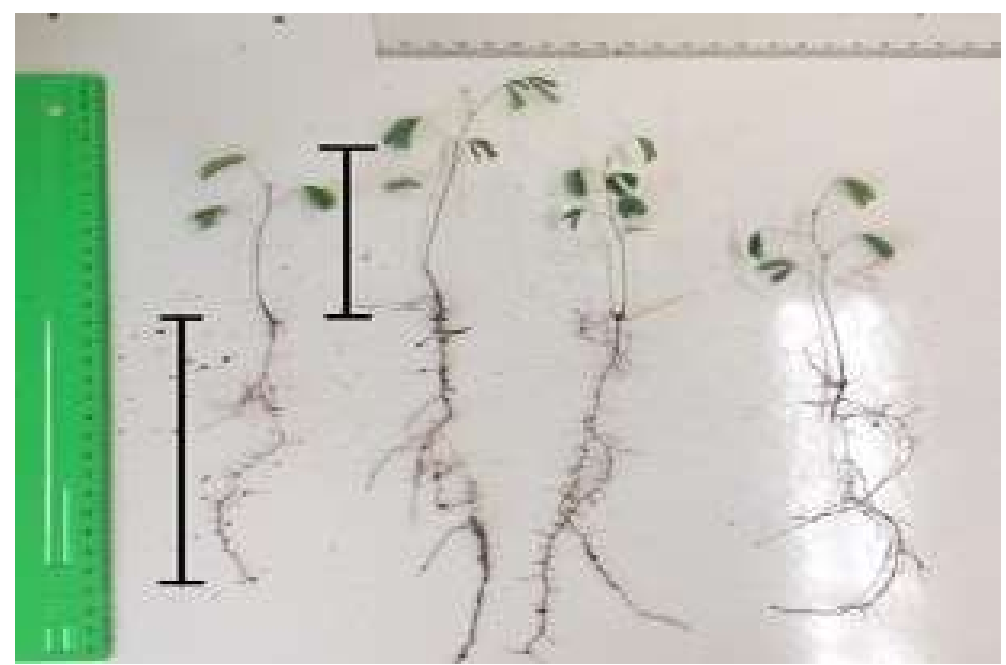

Figura 5: Medida de raiz e folhas da Mimosa bimucronata (DC.) Kuntze.

Passado esse processo os cadinhos são alocados em um dessecador para resfriar e assim ser feita a digestão em $25 \mathrm{~mL}$ de ácida com ácido nítrico $\left(\mathrm{HNO}_{3}\right)$ em um béquer de $100 \mathrm{~mL}$, após a digestão é necessária a filtragem da solução em funil Buchner para a leitura no espectrofotômetro de absorção atômica por chama, para determinar a concentração de contaminantes armazenada em cada amostra da espécie em seu tecido 
vegetal.

Para a medição de ferro, é necessária a construção da curva de calibração que é realizada a partir de cinco concentrações da solução mãe e completada com água deionizada na proporção de $0,1,0,5,1,0,2,0$, $4,0 \mathrm{mg} / \mathrm{L}$ da solução mãe e completando em um béquer de $100 \mathrm{~mL}$ com água deionizada. A solução mãe foi preparada a partir de $10 \mathrm{~mL}$ do padrão analítico $(1.000 \mathrm{mg} / \mathrm{L})$, no caso o ferro, e completada com água deionizada em um balão volumétrico de 1.000 mL, tendo uma solução com a concentração de $10 \mathrm{mg} / \mathrm{L}$.

\section{Digestão Ácida e Espectrometria de Absorção Atômica}

Para ser feita a absorção atômica, é necessária a digestão em ácido para a leitura de quanto a Mimosa bimucronata (DC.) Kuntze absorveu de ferro (Fe) do solo. Após o resfriamento do material calcinado, foi adicionado $25 \mathrm{~mL}$ de ácido nítrico ao material em um béquer de $100 \mathrm{~mL}$ e misturados, ocorrendo assim, a digestão do material coletado.

Após sua digestão é necessária a filtragem da solução para que não entupa o aparelho de espectrometria de absorção atômica e fazendo com que a vida útil do aparelho seja maior e não comprometa os dados analisados, sendo assim, feita cinco vezes para que a amostra fique a mais límpida possível e realocadas em frascos âmbar sendo mantidos na geladeira do laboratório para manter suas propriedades fazendo os testes no dia seguinte. Para a filtragem foi utilizada uma filtração de vidro com uma porcelana para filtrar os sólidos suspensos, juntamente com uma bomba de vácuo para agilizar a filtragem.

Como será feita a medição de ferro, é necessária a construção da curva de calibração que será realizada a partir de cinco concentrações da solução mãe e completada com água deionizada na proporção de $0,1,0,5,1,0,2,0,4,0 \mathrm{mg} / \mathrm{L}$ da solução mãe e completando em um béquer de $100 \mathrm{~mL}$ com água deionizada. A solução mãe foi preparada a partir de $10 \mathrm{~mL}$ do padrão analítico $(1.000 \mathrm{mg} / \mathrm{L})$, no caso o ferro, e completada com água deionizada em um balão volumétrico de $1.000 \mathrm{~mL}$, tendo uma solução com a concentração de 10 $\mathrm{mg} / \mathrm{L}$.

\section{RESULTADOS E DISCUSSÃO}

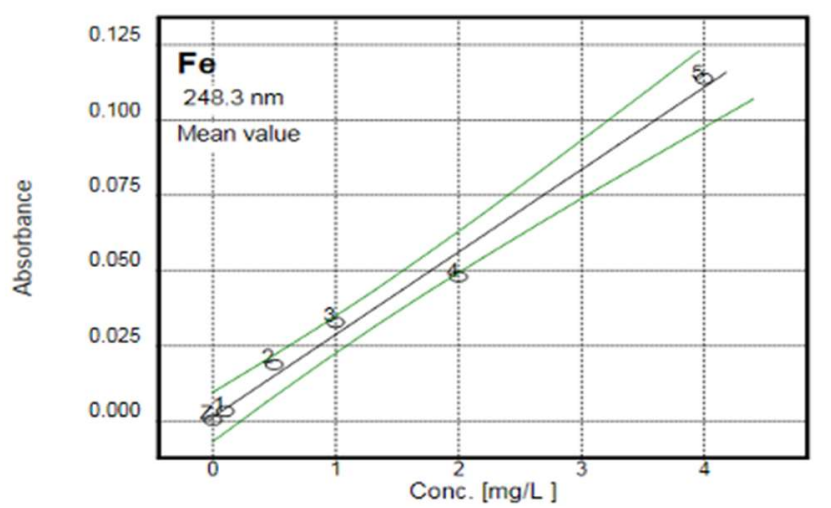

Figura 6: Curva de calibração para o Ferro.

A curva de calibração realizado com cinco concentrações da solução mãe é mostrada na Figura 6. Após notação dos valores de comprimento de raiz e caule e concentração final de ferro nas amostras, esses foram transferidos para uma planilha eletrônico para posterior análise estatística dos dados. Foi proposto o 
teste de Shapiro-Wilk para determinação da normalidade, cujo objetivo é fornecer uma estatística de teste para avaliar se uma amostra tem distribuição normal, podendo ser usado para dados amostrais pequenos ( $\mathrm{n}$ $<50$ ), aplicou-se esse para posteriormente analisar a relação entre os diferentes tratamentos adotados e o comprimento de raiz e caule.

Os resultados observados para o teste de normalidade de Shapiro-Wilk revelam que os dados para os tratamentos nas concentrações $0.086,3$ e 6 mg/kg são não normais para os dados referentes ao comprimento de raiz e também para os tratamentos 0.086 e $6 \mathrm{mg} / \mathrm{kg}$ para comprimento de caule, ou seja, descarta a possibilidade de relação dos tratamentos apontados com o desenvolvimento de comprimento de raiz e caule (Tabela 1 e Tabela 2). Diferente é o observado no tratamento na concentração $12 \mathrm{mg} / \mathrm{kg}$ para raiz e na concentração 3 e 12 mg/kg para caule, que revelou normalidade nos dados, afirmando a existência de diferença do desenvolvimento de comprimento de raiz e caule nessas condições.

Tabela 1: Teste de Shapiro-Wilk para normalidade do comprimento de raiz nas condições de tratamento.

\begin{tabular}{lllll}
\hline Concentração $(\mathrm{mg} / \mathrm{kg})$ & 0.086 & 3 & 6 & 12 \\
\hline Tamanho da amostra $=$ & 25 & 25 & 19 & 41 \\
\hline Média $=$ & 13.98 & 15.8 & 17.1053 & 14.2683 \\
\hline Desvio padrão $=$ & 3.8174 & 5.5827 & 3.7844 & 4.5154 \\
\hline $\mathrm{W}=$ & 0.9698 & 0.9775 & 0.911 & 0.9713 \\
\hline $\mathrm{p}=$ & 0.6363 & 0.8177 & 0.0812 & 0.4867 \\
\hline
\end{tabular}

Tabela 2: Teste de Shapiro-Wilk para normalidade do comprimento de caule nas condições de tratamento.

\begin{tabular}{lllll}
\hline Concentração $(\mathrm{mg} / \mathrm{kg})$ & 0.086 & 3 & 6 & 12 \\
\hline Tamanho da amostra $=$ & 25 & 25 & 19 & 41 \\
\hline Média $=$ & 8.74 & 9.24 & 10.8684 & 11.9488 \\
\hline Desvio padrão $=$ & 2.1704 & 2.2827 & 1.8697 & 2.3054 \\
\hline $\mathrm{W}=$ & 0.9834 & 0.9566 & 0.9602 & 0.9611 \\
\hline $\mathrm{p}=$ & 0.9306 & 0.41 & 0.5604 & 0.3021 \\
\hline
\end{tabular}

Considerando a presença de dados não normais, complementa-se o resultado alcançado com o teste de variância ANOVA fatorial caule x raiz, os resultados encontrados estão indicados na Tabela 3.

Tabela 3: Teste ANOVA fatorial caule $\mathrm{x}$ raiz para variância dos comprimentos de raiz e caule nos diferentes tratamentos de concentração de ferro.

\begin{tabular}{|c|c|c|c|}
\hline FONTES DE VARIAÇÃO & $\mathrm{GL}$ & SQ & QM \\
\hline Tratamentos & 7 & 2105.7866 & 300.8267 \\
\hline Blocos & 2 & 960.9782 & 480.4891 \\
\hline Interação & 14 & 1580.884 & 112.9203 \\
\hline \multirow[t]{2}{*}{ Erro } & 480 & 19676.0667 & 40.9918 \\
\hline & --- & --- & --- \\
\hline $\mathrm{F}($ Tratamentos $)=$ & 7.3387 & --- & --- \\
\hline Graus de liberdade $=$ & 7,480 & --- & --- \\
\hline p (Tratamentos) & $<0.0001$ & --- & --- \\
\hline $\mathrm{F}$ (Blocos) $=$ & 11.7216 & --- & --- \\
\hline Graus de liberdade $=$ & 2,480 & --- & --- \\
\hline$p($ Blocos $)=$ & 0.0001 & --- & --- \\
\hline $\mathrm{F}$ (Interação) = & 2.7547 & --- & --- \\
\hline Graus de liberdade $=$ & 14,480 & --- & --- \\
\hline $\mathrm{p}($ Interação $)=$ & 0.0008 & --- & --- \\
\hline
\end{tabular}

Obtiveram-se valores significativos de erro na análise de variância, portanto conclui-se que houve diferença no comprimento de raiz e caule para as diferentes concentrações de ferro nos 3 tratamentos propostos. Dito isso se apresenta a análise descritiva que representa as medidas encontradas de 
comprimento de raiz e caule na Figura 7 e Tabela 4.

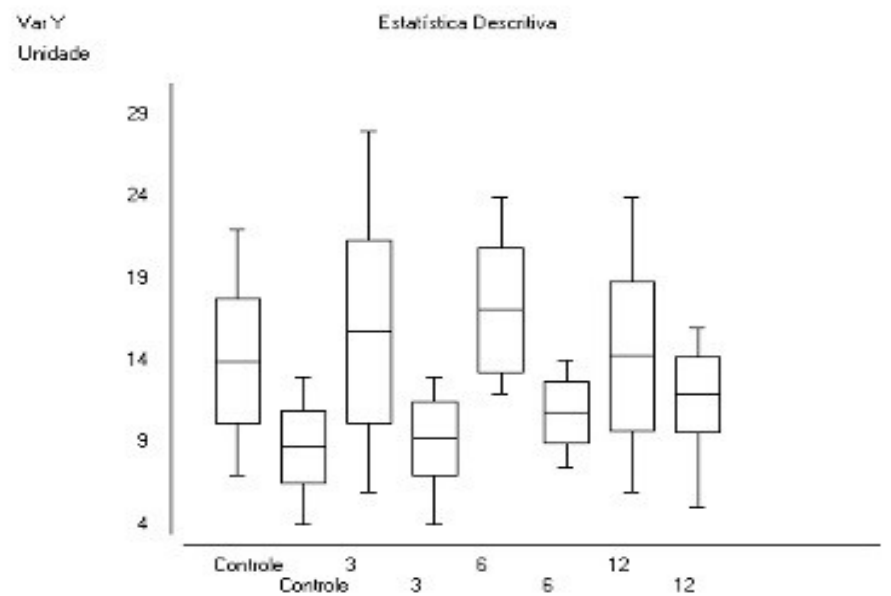

Figura 7: Análise descritiva que representa as medidas encontradas de comprimento de raiz e caule.

Tabela 4: Medidas de comprimento de raiz e caule nas diferentes concentrações.

\begin{tabular}{|c|c|c|c|c|c|c|c|c|}
\hline & \multicolumn{2}{|l|}{ Controle } & \multicolumn{2}{|l|}{3} & \multicolumn{2}{|l|}{6} & \multicolumn{2}{|l|}{12} \\
\hline & Raiz & Caule & Raiz & Caule & Raiz & Caule & Raiz & Caule \\
\hline Tamanho da amostra = & 25 & 25 & 25 & 25 & 19 & 19 & 41 & 41 \\
\hline Mínimo & 7 & 4 & 6 & 4 & 12 & 7.5 & 6 & 5 \\
\hline Máximo & 22 & 13 & 28 & 13 & 24 & 14 & 24 & 16 \\
\hline Amplitude Total & 15 & 9 & 22 & 9 & 12 & 6.5 & 18 & 11 \\
\hline Mediana & 14 & 8.5 & 16 & 10 & 16 & 11 & 14 & 12 \\
\hline Primeiro Quartil (25\%) & 11 & 7.5 & 12 & 8 & 14 & 10 & 11 & 11 \\
\hline $\begin{array}{l}\text { Terceiro Quartil } \\
(75 \%)\end{array}$ & 16.5 & 10.5 & 20 & 11 & 20 & 12 & 18 & 13.4 \\
\hline Desvio Interquartílico & 5.5 & 3 & 8 & 3 & 6 & 2 & 7 & 2.4 \\
\hline Média Aritmética & 13.98 & 8.74 & 15.8 & 9.24 & 17.1053 & 10.8684 & 14.2683 & 11.9488 \\
\hline Variância & 14.5725 & 4.7108 & 31.1667 & 5.2108 & 14.3216 & 3.4956 & 20.3887 & 5.3151 \\
\hline Desvio Padrão & 3.8174 & 2.1704 & 5.5827 & 2.2827 & 3.7844 & 1.8697 & 4.5154 & 2.3054 \\
\hline Erro Padrão & 0.7635 & 0.4341 & 1.1165 & 0.4565 & 0.8682 & 0.4289 & 0.7052 & 0.36 \\
\hline Coeficiente de Variação & $27.31 \%$ & $24.83 \%$ & $35.33 \%$ & $24.70 \%$ & $22.12 \%$ & $17.20 \%$ & $31.65 \%$ & $19.29 \%$ \\
\hline Assimetria (g1) & \begin{tabular}{|l|}
-0.0691 \\
\end{tabular} & \begin{tabular}{|l|}
-0.0365 \\
\end{tabular} & 0.1 & \begin{tabular}{|l|}
-0.5897 \\
\end{tabular} & 0.5139 & 0.0666 & 0.0416 & $\mid-0.6771$ \\
\hline Curtose (g2) & -0.5221 & -0.3064 & -0.5763 & \begin{tabular}{|l|}
-0.1142 \\
\end{tabular} & -1.129 & -0.6377 & \begin{tabular}{|l|l|}
-0.7918 \\
\end{tabular} & 1.1213 \\
\hline Média Harmônica & 12.8537 & 8.1528 & 13.6359 & 8.5361 & 16.3658 & 10.5556 & 12.7074 & 11.3772 \\
\hline $\mathrm{N}$ (média harmônica) & 25 & 25 & 25 & 25 & 19 & 19 & 41 & 41 \\
\hline Média Geométrica & 13.4368 & 8.4603 & 14.7593 & 8.919 & 16.7246 & 10.7132 & 13.5124 & 11.6928 \\
\hline $\mathrm{N}$ (média geométrica) & 25 & 25 & 25 & 25 & 19 & 19 & 41 & 41 \\
\hline Variância (geom.) & 1.0389 & 1.0319 & 1.0693 & 1.0363 & 1.0206 & 1.0135 & 1.0532 & 1.0217 \\
\hline Desvio Padrão (geom.) & 1.3449 & 1.3083 & 1.481 & 1.3317 & 1.2417 & 1.1921 & 1.4127 & 1.2491 \\
\hline
\end{tabular}

A Tabela 5 demonstra os resultados obtidos para concentração após o processo de adsorção atômica, esses valores representam a concentração absorvida pelo material vegetal das espécies que crescerem.

Tabela 5: Concentração absorvida pelo material vegetal dos indivíduos que se desenvolveram nas diferentes concentrações de ferro.

\begin{tabular}{l|l}
\hline & Concentração $\mathrm{mg} / \mathrm{kg}$ \\
\hline A1 CONTROLE & 82.16918845 \\
\hline A2 CONTROLE & 57.10573534 \\
\hline A3 CONTROLE & 94.56515444 \\
\hline A1 [0.3] & 243.8598901 \\
\hline A2 [0.3] & 247.4212185 \\
\hline A3 [0.3] & 197.4843081 \\
\hline A1 [0.6] & 371.6135458 \\
\hline A2 [0.6] & 270.8983209 \\
\hline A1 [1.2] & 172.6671664 \\
\hline
\end{tabular}


$\mathrm{A} 2[1.2]$

A3 [1.2]

A fim de comprovar a existência de diferentes resultados de concentração absorvida pelas amostras foi proposto aplicação de teste t para amostras paramétrica, executou-se par a par com o controle, conforme Tabelas 6, 7 e 8.

Tabela 6: Teste t para absorção das amostras de controle e com concentração $3 \mathrm{mg} / \mathrm{kg}$ de ferro.

\begin{tabular}{l|l|l}
\hline Indivíduos & 3 & 3 \\
\hline Média & 77.9467 & 229.5885 \\
\hline Desvio Padrão & 19.0833 & 27.86 \\
\hline Erro Padrão & 11.0178 & 16.085 \\
\hline Desv. Padrão da Diferença & 44.5563 & --- \\
\hline Erro Padrão da Diferença & 25.7246 & --- \\
\hline Média das diferenças & -151.6418 & --- \\
\hline (t) & -5.8948 & --- \\
\hline Graus de Liberdade & 2 & --- \\
\hline$(p)$ unilateral = & 0.0138 & --- \\
\hline$(p)$ bilateral $=$ & 0.0276 & --- \\
\hline IC $(95 \%)$ & -262.3347 a -40.9488 & --- \\
\hline $\mathrm{IC}(99 \%)$ & -406.9584 a 103.6749 & --- \\
\hline
\end{tabular}

Tabela 7: Teste t para absorção das amostras de controle e com concentração $6 \mathrm{mg} / \mathrm{kg}$ de ferro.

\begin{tabular}{l|l|l}
\hline Indivíduos & 3 & 3 \\
\hline Média & 77.9467 & 271.7263 \\
\hline Desvio Padrão & 19.0833 & 99.4758 \\
\hline Erro Padrão & 11.0178 & 57.4324 \\
\hline Desv. Padrão da Diferença & 107.0831 & --- \\
\hline Erro Padrão da Diferença & 61.8244 & --- \\
\hline Média das diferenças & -193.7797 & --- \\
\hline (t) & -3.1344 & --- \\
\hline Graus de Liberdade & 2 & --- \\
\hline$(p)$ unilateral = & 0.0442 & --- \\
\hline$(p)$ bilateral $=$ & 0.0884 & --- \\
\hline IC $(95 \%)$ & -459.8102 a 72.2509 & --- \\
\hline IC $(99 \%)$ & -807.3872 a 419.8279 & \\
\hline & &
\end{tabular}

Tabela 8: Teste t para absorção das amostras de controle e com concentração $12 \mathrm{mg} / \mathrm{kg}$ de ferro.

\begin{tabular}{l|l|l}
\hline Indivíduos & 3 & 3 \\
\hline Média & 77.9467 & 582.3418 \\
\hline Desvio Padrão & 19.0833 & 306.3052 \\
\hline Erro Padrão & 11.0178 & 176.8454 \\
\hline Desv. Padrão da Diferença & 288.2832 & --- \\
\hline Erro Padrão da Diferença & 166.4404 & --- \\
\hline Média das diferenças & -504.3951 & --- \\
\hline (t) & -3.0305 & --- \\
\hline Graus de Liberdade & 2 & --- \\
\hline (p) unilateral = & 0.0469 & --- \\
\hline (p) bilateral = & 0.0938 & --- \\
\hline IC $(95 \%)$ & -1220.5881 a 211.7978 & - \\
\hline IC (99\%) & -2156.3159 a 1147.5257 & - \\
\hline
\end{tabular}

Diante dos resultados apresentados conclui-se que se desconsidera a influência do tratamento na absorção apenas para a amostra com concentração $3 \mathrm{mg} / \mathrm{kg}$, entretanto, nas concentrações $6 \mathrm{mg} / \mathrm{kg}$ e 12 $\mathrm{mg} / \mathrm{kg}$ é possível afirmar que houve sim uma absorção considerável de ferro, especialmente na concentração $12 \mathrm{mg} / \mathrm{kg}$ onde o $\mathrm{p}$ (bilateral) alcança 0,0938.

Avaliando comparativamente as Tabelas 6, 7 e 8 com a Tabela 5 observa-se que a maior concentração 
de ferro nas plantas do bloco amostral está na concentração $12 \mathrm{mg} / \mathrm{kg}$ de ferro, que alcançou o valor de $909.2408257 \mathrm{mg} / \mathrm{kg}$ de ferro, valor quase 10 vezes superior que a maior concentração encontrada no controle, fato esse que reforça o argumento de que houve absorção de ferro.

O ferro nas espécies vegetais está associado a atividades metabólicas, sendo indispensável nos processos de respiração, fotossíntese, fixação de $\mathrm{N}_{2}$ e transferência de elétrons pelo ciclo $\mathrm{Fe}^{2+}$ e $\mathrm{Fe}^{3+}$ (ALEXANDRE et al., 2012). A Mimosa bimucronata (DC.) Kuntze, por ser uma dicotiledônea apresenta a seguinte estratégia de absorção do ferro, incialmente ela reduz o $\mathrm{Fe}^{3+} \mathrm{em} \mathrm{Fe}^{2+}$, pela acidificação da rizosfera, realizada pela extrusão de prótons pela H+-ATPases de membrana plasmática. Após realizar a redução, o Fe ${ }^{2+}$ é transportado por transportadores específicos de membrana (IRT) para o interior das células (ALEXANDRE et al., 2012).

Para Silva et al. (2007) a regulagem de metais pesados na rizosfera e o acúmulo dos mesmos nas raízes, preservando a sua integridade e função primárias, junto com a baixa translocação para a parte aérea são mecanismos pelos quais o sistema radicular pode auxiliar a tolerância de espécies a metais pesados. Assim, Dan (2001) escreve que todo organismo vivo tem a capacidade de tolerar uma pequena porção de metais pesados não essenciais e utilizar dos mesmos para o crescimento, todavia essa capacidade reduz à medida que a concentração aumenta.

\section{CONCLUSÕES}

Um dos metais pesados contaminantes mais comuns no solo é o Ferro e está causa grande degradação de áreas e difícil revegetação onde há contaminação. Contudo, o Ferro em concentrações adequadas, são essenciais para o desenvolvimento dos organismos, pois estão presentes em vários processos biológicos, além de comporem estruturas proteicas (ALEXANDRE et al., 2012).

Partindo disto e dos testes feitos neste trabalho, podemos afirmar que a planta absorveu o Ferro do solo, porém como não foi feito a análise do solo, não é possível avaliar a eficiência de remoção da planta. Caso houvesse a possibilidade de mais tempo, seria viável refazer o teste e analisar o solo.

Mesmo com possíveis melhoras para trabalhos futuros, a Mimosa bimucronata (DC.) Kuntze, cumprio o objetivo inicial, que é utilizar o Ferro para formação da planta, mesmo havendo concentrações de Ferro na semente da planta, é possível afirmar isso, com base no aumento na quantidade de Ferro encontrada nas amostras, onde, as amostras das plantas que estavam nas maiores concentrações, aparecem muito maiores em relação as plantas que foram alocadas no controle.

\section{REFERÊNCIAS}

ALEXANDRE, J. R.; OLIVEIRA, M. L. F.; SANTOS, T. C.; CANTON, G. C.; MELO, J.; EUTRÓPIO, F. J.; CRUZ, Z. M.; DOBBSS, L. B.; RAMOS, A. C.. Zinco e ferro: de micronutrientes a contaminantes do solo. Natureza, v.10, n.1, p.23-28, 2012.

AMADO, S.; CHAVES FILHO, J. T.. Fitorremediação: uma alternativa sustentável para remedição de solos contaminados por metais pesados. Natureza, v.13, n.4, p.158-164, 2015.

BIOTECH. Método utiliza plantas para limpar solos contaminados com metais pesados. BIOTECH, 2006.

COUTINHO, H. D.; BARBOSA, A. R.. Fitorremediação: Considerações gerais e características de utilização. Silva Lusitana, v.15, n.1, p.103-117, 2007. 
DAN, T. V.. Phytoremediation of metal contaminated soils: Metal tolerance and metal accumulation in Pelargonium SP. These (Doctored) - The University of Guelph, Ottawa, 2001.

LEVY, D. B.; BARBARICK, K. A.; SIEMER, E. G.; SOMMERS, L. E.. Distribution and partitioning of trace metals in contaminated soils near Leadville, Colorado. J. Environ. Qual., v.21, p.185-195, 1992.

LI, Z.; SHUMAN, L. M.. Heavy metal movement in metalcontaminated soil profiles. Soil Sci., v.161, p.656-666, 1996.

RIBEIRO FILHO, M. R.; SIQUEIRA, J. O.; CURI, N.; SIMÃO, J. B. $P$.. Fracionamento e biodisponibilidade de metais pesados em solo contaminado, incubado com materiais orgânicos e inorgânicos. Revista Brasileira de Ciência do Solo, v.25, n.2, 2001.

RAMALHO, J. F. G. P.; AMARAL SOBRINHO, N. M. B.;
VELLOSO, A. C. X.. Contaminação da microbacia de Caetés com metais pesados pelo uso de agroquímicos. Pesquisa Agropecuária Brasileira, v.35, n.7, p.1289-1303, 2000.

SIQUEIRA, J. O.; MOREIRA, F. M. S.; LOPES, A. S.; GUILHERME, L. R. G.; FAQUIN, V.; FURTINI NETO, A. E.; CARVALHO, J. G.. Inter-relação fertilidade, biologia do solo e nutrição de plantas. Lavras: Universidade Federal de Lavras, 1999.

SILVA, M. L. S.; VITTI, G. C.; TREVIZAM, A. R.. Concentração de metais pesados em grãos de plantas cultivadas em solo com diferentes níveis de contaminação. Pesq. Agropec. Bras., Brasília, v.42, n.4, p.527-535, 2007.

TAVARES, S. R. L.. Fitorremediação em solo e água de áreas contaminadas por metais pesados provenientes da disposição de resíduos perigosos. Tese (Doutorado) Universidade Federal do Rio de Janeiro, Rio de Janeiro, 2009.

A CBPC - Companhia Brasileira de Produção Científica (CNPJ: 11.221.422/0001-03) detém os direitos materiais desta publicação. Os direitos referem-se à publicação do trabalho em qualquer parte do mundo, incluindo os direitos às renovações, expansões e disseminações da contribuição, bem como outros direitos subsidiários. Todos os trabalhos publicados eletronicamente poderão posteriormente ser publicados em coletâneas impressas sob coordenação da Sustenere Publishing, da Companhia Brasileira de Produção Científica e seus parceiros autorizados. Os (as) autores (as) preservam os direitos autorais, mas não têm permissão para a publicação da contribuição em outro meio, impresso ou digital, em português ou em tradução. 